\title{
The use of the International Classification of Functioning, Disability and Health, version for Children and Youth (ICF-CY), in Portuguese special education assessment and eligibility procedures: the professionals' perceptions
}

Manuela Sanches-Ferreira*, Monica Silveira-Maia and Silvia Alves

Special Education Department, School of Education, Porto Polytechnic, Porto, Portugal

Portugal was the first country decreeing the mandatory use of the International Classification of Functioning, Disability and Health: Child and Youth (ICF-CY) framework for guiding special education assessment process and to base eligibil- ity decision-making on students' functioning profiles - in contrast with tradi- tional approaches centred on medical diagnosis. Considering the conceptual and pragmatic adjustments underlying this change, this study intends to explore how the professionals involved in assessment procedures perceive the impact of the ICF-CY use. Inscribed in an external evaluation commissioned by the Portuguese Ministry of Education, a content analysis was conducted over 33 focus groups composed of 192 educational professionals selected from a strati- fied random sampling design. Professionals' opinions revealed that the ICF-CY use supported a better understanding of students' functioning by prompting the description of the environmental influence on students' participation. Challenges were pointed out regarding the ICF-CY use, namely: (1) the need of assessment tools that can provide information about the environmental influences on stu- dents' functioning ; (2) the establishment of collaboration mechanisms between professionals; and (3) the professionals' ICF-CY training. Based on these three challenges/dimensions, recommendations were drawn in order to prompt a multidimensional approach on educational assessment and intervention planning.

Keywords: students in need of additional supports; inclusion; education policy; assessment; eligibility ; International Classification of Functioning, Disability and Health: Child and Youth (ICF-CY) 


\section{Introduction}

Any policy change intends a renewed connection between the practice regulation and the state of the art of knowledge, aiming to narrow the gap between theory and empirical data (Shonkoff 2000). The achievement of this connection has been inspir- ing successive law reformulations in the way that educational responses are concep- tualised and organised, specifying new directions for the questions: (1) who is eligible for special education services, and how?; (2) where should students be placed or get support?; and (3) what curriculum, resources, and teaching methods/ strategies should be implemented? And by whom?

Following the same principle, the Portuguese political reform on special education introduced by the Decree-Law No. 3/2008 - added new directions to regulate and define mechanisms for equitable resources distribution, and to respond to students' needs. The assessment and eligibility processes - the 'who' and 'how' questions - were the main points of change, as a consequence of the compulsory use of the International Classification of Functioning, Disability and Health : Child and Youth (ICF-CY) as reference framework. This change demanded conceptual and pragmatic adjustments from all professionals and school organisation.

\section{The ICF-CY use in educational contexts}

Long before the ICF-CY publication (WHO 2001, 2007), it was already recognised that impairment-centred approaches were not able to inform interventions focused on partic- ipation outcomes. It was also assumed that for being congruent with the state of art of knowledge and with a set of principles and values underlying different Human Rights conventions and documents (e.g. Unit Nations Convention on the Rights of Persons with Disabilities 2006), the professionals' practices should be focused on the interaction between the child and the environment (Sanches-Ferreira, Lopes-dos-Santos, et al. 2013; Simeonsson, Simeonsson, and Hollenweger 2008). This interactional perspective was already considered in 1978, when Bijou and Baer stated that we cannot analyze a child without reference to an environment, nor is it possible to analyze an environment without reference to a child. The two form an inseparable unit consisting of an interrelated set of variables, or an interactional field. $(1978,29)$

It was anchored on this principle, that the ICF-CY is an interesting framework, not only on educational research and politics spheres but also on planning educational responses (Norwich 2008).

In the last four decades, several models were developed ascribing different mean- ings 
to disability concept and informing differently 'what to observe' and 'what to do' on assessment and intervention processes (Altman 2001). Consolidating an evo- lutionary process from individually oriented approaches towards a biopsychossocial perspective, the ICF-CY introduced substantial changes in disability description by considering: (1) a conceptual component explicitly dedicated to the environmental role on disablement and functioning processes; (2) reciprocal relationships between conceptual components; and (3) a neutral and positive language defining different components (WHO 2007).

The ICF-CY is, then, a taxonomy that provides a universal and comprehensive framework for the description of human functioning and disability. Conceptualising the human functioning as an interaction between individual's features and social and physical environment factors, the ICF-CY taxonomy is composed of a list of alpha- numeric codes organised into four main components: Body Functions; Body Struc- tures; Activities and Participation; and Environmental Factors. As defined on the ICF-CY manual (WHO 2007, 10), the Body Functions component encompasses the 'physiological functions of body systems (including psychological functions)', and the Body Structures the 'anatomical parts of the body such as organs, limbs and their components'. Activities refers to the 'execution of a task or action' and the Participation to the 'involvement in a life situation' (WHO 2007, 10). The Environ- mental Factors component incorporates 'physical, social and attitudinal environment in which people live and conduct their lives', and allows the distinction of environ- mental factors acting as barriers or facilitators to individuals' functioning.

By assigning a qualifier after the alphanumeric codes, the magnitude of the func- tioning or disability in the Body Functions and Structures, and Activities and Partici- pation components, or the extent to which an environmental factor is a facilitator or barrier, are described. Qualifiers range from 0 (no problem) to 4 (complete problem) on Body Functions, Body Structures, and Activities and Participation components. Environmental Factors component uses the same 0-4 scale, but a plus sign is used to denote facilitators. Two qualifiers are used to qualify Activities and Participation domains: (1) capacity 'describing an individual's ability to execute a task or an action'; and (2) performance 'describing what an individual does in his or her cur- rent environment' (WHO 2007, 15).

Through these structural and conceptual characteristics the ICF-CY guides, then, a description of comprehensive functioning profiles, documenting not only, chil- dren's responses to environmental demands but also environmental responses to children's needs, is made. By providing a multidimensional spectrum of information, the ICF-CY use has been, then, recognised as a way of turning workable a holistic approach that can support inclusive processes (Florian et al. 2006; Simeonsson 2006 ; Simeonsson, Simeonsson, and Hollenweger 2008). Furthermore, the descrip- tion of functioning 
profiles as a person-environment dynamic relation would support individualised practices, prompting the connection between assessment and interven- tion planning (Hollenweger 2011, 2008; Norwich 2008; Silveira-Maia et al. 2012).

Based on such assumptions, a growing number of international pilot experiences have been conducted to study the ICF-CY use on special education assessment and eligibility processes - e.g. in Switzerland (Hollenweger 2011); in Italy (De Polo et al. 2009; Fusaro, Maspoli, and Vellar 2009); and in Japan (Tokunaga 2008). Portugal was the first country decreeing - on special education legislation (i.e. Decree-Law No. 3/2008) the compulsory use of the ICF-CY as a reference framework on assessment and eligibility processes.

How was the !CF-CY use conceived on Portuguese special education assessment and eligibility processes?

Over the last decades, Portugal has ratified important international agreements and conventions (e.g. UNESCO's Salamanca Statement and Framework for Action in Special Needs Education 1994; United Nations Convention on Rights of People with Disabilities 2006) assuming as guiding principle of educational policies and prac- tices the development of 'equal opportunities in terms of genuine access to learning experiences that respect individual differences and quality education for all focused upon personal strengths rather than weaknesses' (European Agency for Special Needs and Inclusive Education 2009). The intent of putting this way of thinking and of conceiving education into practices has been prompting the shift from deficits- based assessments towards approaches more focused on functional and participation dimensions.

Assuming the limited utility of one-dimensional and categorical disability classifications for educational planning (Ebersold and Evans 2008), the Portuguese DecreeLaw No. 3/2008 promoted the replacement of medical diagnosis by a description of the students' functioning profile - described with reference to the ICF-CY framework - to base the eligibility decision-making. This change intended - in a congruent manner with the international guidance (European Agency for Special Needs and Inclusive Education 2011) - to accomplish a multidimensional approach on assessment and eligibility processes.

In light of these core conceptual reasons underlying the introduction of the ICF-CY use, below will be described the steps and procedures embodying current Portuguese special education assessment process.

As represented in the Figure 1, once the student is referenced (step 1) as having difficulties that may require additional support needs there is an initial assessment process 
(step 2) from which results a decision about the need of developing a spec- ialised assessment.

In case of deciding that the specialised assessment is not necessary (step 3), dif- ferent predefined measures are activated in order to support the student's learning (step 7). If the specialised assessment (step 4) is considered necessary, then an inter- disciplinary team is composed demanding the involvement of regular and special education teachers, parents and, if necessary, other disciplines or services (health ser- vices and specialised resource centres). It is at this stage that the ICF-CY use - based yet on a Portuguese non-official translation of the ICF-CY manual - as an assessment framework becomes compulsory.

The assessment process is then planned through the identification of ICF-CY categories of students functioning that are in need of assessment. Information sources and assessment methods and measures are then defined to gather the intended information.

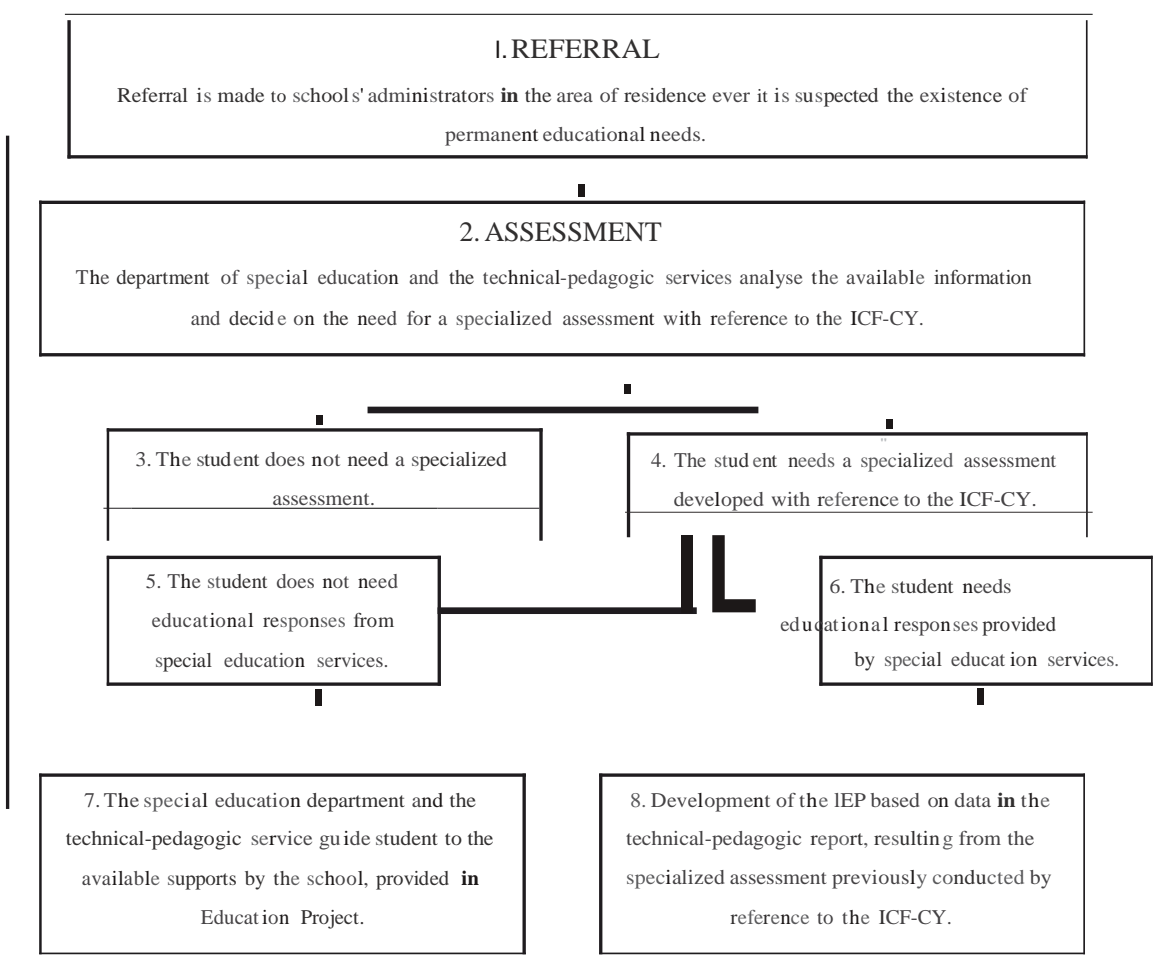

Figure 1. Portuguese special education assessment and intervention processes (adapted from Capucha et al. 2008). 
Based on assessment information a technical and pedagogical report is produced (step 6), documenting a functioning profile that should characterise students' Activi- ties and Participation as a result of the dynamic interaction between Body Functions and Structures and the Environmental Factors. It's on the understanding of this dynamic interaction that educational responses should be designed (step 7 or 8 ) - which may or may not involve the activation of special education services.

In order to differentiate those students whose difficulties demand the allocation of additional supports from those whose needs can be met without activating special education services, this Decree-Law states as eligibility criteria

students with significant limitations in terms of activity and participation in one or more life domains due to permanent functional and structural issues, which result in continued difficulty in terms of communication, learning, mobility, autonomy, interper- sonal relationships and social involvement. (European Agency for Special Needs and Inclusive Education 2009)

Based on the congruence between the functioning profile of the student and the above definition of the target population for special education services, the interdis- ciplinary team - responsible for the specialised assessment - proceeds, then, to the eligibility decision-making. A recent study - from the authors of this paper (Sanches-Ferreira, Simeonsson, et al. 2013) - revealed that the decision on the eligibility for special education services is based on the severity of Activities and Participation limitations and restrictions and of Body Functions impairments. The mean of the qualifiers assigned to Body Functions and Activities and Participation ranged from 2 (moderate problem) to 3 (severe problem) on the functioning profiles of eligible students, while on the noneligible students the qualifiers mean ranged from 1 (mild problem) to 2 (moderate problem).

In addition to the ICF-CY use, the Decree-Law No. 3/2008 introduced other substantial changes on special education needs assessment and intervention, namely by:

(1) assigning the role of individualized education plan (IEP) coordinator to the regu- lar education teacher; (2) conceiving regular schools of reference in areas of low vision and blindness and deafuess, and specialised units to support the education of students with autism and multiple disabilities; and (3) transforming special schools into inclusive resource centres (IRC). 
In order to understand how this decree-law has been implemented and what out- comes were achieved, the Portuguese Ministry of Education requested a national eval- uation of its implementation, specifically with regard to the ICF-CY use. Developed with the consultancy of Rune Simeonsson - chair of the WHO Working Group on the Version of ICF for Children and Youth the evaluation project comprised three differ- ent studies. The first one was designed with the aim of describing the functioning pro- file of eligible and noneligible students for special education services, and of identifying who is involved and which tools are used on the assessment process (Sanches-Ferreira, Simeonsson, et al. 2013). The second study intended to explore the professionals' perceptions about the implementation of the Decree-Law No. 3/2008. Identifying and prioritising the greater difficulties of and supports needed for the Decree-Law implementation were the aims of the third study (Sanches-Ferreira et al. 2010). From this evaluation resulted a final report, describing and analysing the cur- rent practices of assessment and eligibility in Portugal and addressing key recommen- dations to improve the decree-Law implementation (SanchesFerreira et al. 2010).

In a moment that international efforts have been developed to implement multidimensional approaches on assessment and eligibility processes (e.g. De Polo et al. 2009; Fusaro, Maspoli, and Vellar 2009; Hollenweger 2011), with this study we intend to share the Portuguese experience, documenting how educational profession- als perceived the ICFCY use as reference framework for assessment and eligibility processes. Based on data obtained through focus groups, the present study aims to explore the: (1) advantages and disadvantages perceived on the ICF-CY use to sup- port a better understanding of the students' needs; (2) challenges and difficulties faced; and (3) changes or supportive responses to improve its use.

\section{Methods}

This paper derived from a larger study regarding the national evaluation of the Decree-Law No. 3/2008 implementation that made use of different research meth- ods, namely : case studies - documental analysis of students' individual processes (Sanches-Ferreira, Simeonsson, et al. 2013) and the analysis of professionals' per-ceptions through survey and focus group methodologies (Sanches-Ferreira et al. 2010). With the specific aim of exploring and discussing professionals' perceptions about the ICF-CY use, this paper is based on focus group method. 



\section{Participants}

The subjects of this study were educational professionals involved in the decree-law implementation, from 33 schools groups/units - representing $4 \%$ of the total number of schools units/groups of continental Portugal. As autonomous regions with their own political and administrative statute, Azores and Madeira islands were excluded from the sampling process. In order to gather a representative sample of national reality, the selection of the participant schools groups/units was based on random sampling, stratified according to the total number of schools in each five Regional Boards of Education in Portugal: 33\% from north, $22 \%$ from centre, $31 \%$ from Lisbon, 7\% from Alentejo and 6\% from Algarve.

An invitation letter was sent to the school principals, requesting the participation of the persons generally involved in specialised assessment processes on the focus group, specifically: (1) one element from the school board responsible for the orga- nisation of special education services; (2) one special education teacher; (3) one reg- ular education teacher from 1st grade and others from the 2nd and 3rd grades, whose classrooms included students with additional support needs; (4) one psychol- ogist; (5) when available in school, professionals from IRC (one speech therapist or one occupational therapist); and (6) parents of students with additional support needs. Once there were no verbal interventions from parents with regard to the ICF- CY use, their participation was excluded from the following analysis.

The examined 33 focus groups involved, then, the participation of 192 profes- sionals: 41 special education teachers; 34 elements from the school board; 80 regular education teachers; 27 psychologists; and 10 professionals from ICR (inclusive research centres). In mean, each focus group was composed of six professionals: one special education teacher, one element from the school board, two regular edu-cation teachers (representing different grades), one psychologist and, when available, occupational or speech therapists.

\section{Data collection}

As mentioned, focus group meetings were arranged to get professionals' insights about experiences and opinions related to decree-law implementation.

Based on the central steps of the decree-law and on the case studies' results (vd. Sanches-Ferreira, Simeonsson, et al. 2013), an interview guide was developed in order to address the main questions underlying the Decree-Law No. 3/2008 imple- mentation. Six discussion topics were included in the interview guide: (1) goal and underlying principles of the Decree-Law No. 3/2008; (2) assessment process using the ICF-CY as reference 
framework; (3) regular education teachers, parents and other professionals' involvement in the assessment process and in the individualised educa- tional programme (IEP) design; (4) collaboration practices between school-based and external professionals; (5) existing supports for eligible and non-eligible students; and (6) general perceptions about the decree-law and suggestions for change.

Three pilot focus groups were held in order to evaluate the structure and content suitability of the interview guide, from which further adjustments were made. The final version of the interview guide followed a hierarchical organisation, introducing each of the above-mentioned six topics, first, through open and broad questions and, second, trough more specific questions.

The focus discussions were led by a facilitator and took approximately two hours.

\section{Data analysis}

After the transcription of the focus groups, the data were classified in units of mean- ing, categories and themes following the content analysis proposed by Bardin (1977). The analysis of the gathered material was deepened, disagreements were resolved in debriefing sessions and, finally, the full analysis was consolidated. Each unit of meaning was established at the paragraph level. Data from units of meaning were coded according to categories - each one pertained to only one category - wherever their content allowed the classification of constitutive meaning (Table 1). Categories were assigned to themes, which resulted from discussion topics of the interview guide.

The number of units of meaning within each category was counted. The mean- ings of the categories are examined in the results section, making use of representa- tive sentences to report professionals' opinions. 
Table 1. Examples of meaning units composing identified categories.

\begin{tabular}{|c|c|c|}
\hline Theme & Categories & Examples of meaning units \\
\hline \multirow[t]{3}{*}{$\begin{array}{l}\text { Assessment process } \\
\text { using the ICF-CY as } \\
\text { reference framework }\end{array}$} & $\begin{array}{l}\text { ICF-CY utility for special } \\
\text { education assessment and } \\
\text { eligibility purposes }\end{array}$ & $\begin{array}{l}\text { '(...) The ICF-CY use helps me to } \\
\text { better understand the child and his } \\
\text { needs' }\end{array}$ \\
\hline & $\begin{array}{l}\text { Underlying procedures on } \\
\text { the ICF-CY use }\end{array}$ & $\begin{array}{l}\text { '(...) There is a challenge on the } \\
\text { decision-making about the most } \\
\text { appropriate qualifiers to describe } \\
\text { students functioning' }\end{array}$ \\
\hline & $\begin{array}{l}\text { Implied factors on the ICF- } \\
\text { CY use }\end{array}$ & $\begin{array}{l}\text { '(...) the availability of assessment } \\
\text { tools would be useful to support } \\
\text { the use of the ICF-CY framework' }\end{array}$ \\
\hline
\end{tabular}


Three co-researchers reviewed the categorisation of the units of meaning in themes and categories. Disagreements on the way data were labelled and sorted were discussed and a consensus was achieved. During content analysis process, positive reliability indicators were obtained - with an agreement of 90-95\% between research peers.

\section{Results}

The mandatory use of the ICF-CY as reference framework for assessment and eligi- bility processes embodied a substantial change in educational policies and practices. This study intends to explore professionals' perceptions about the perceived advan- tages, challenges and needs emerging from the ICF-CY use in assessment and eligi- bility processes.

The analysis of these perceptions was based on a total of $3663 \mathrm{~min}$ of examined discourse. As shown in Table 2, the special education teacher has had an important role during focus group discussions, with a mean number of spoken words and ver- bal interventions that suggest a greater participation of this professional group. Based on the same data, school principals and psychologists were the second and third more participative groups.

The percentage of meaning units found in each professional group discourse seems to indicate that the following analysis was strongly grounded in special edu-cation teachers and school principals' opinions, with more than $57 \%$ of the exam- ined meaning units being produced by these professionals ' groups.

Among the total 2589 units of meaning, 326 (12.59\%) referred to categories composing the ICF-CY discussion topics (i.e. theme 'assessment process using the ICF-CY as reference framework'). Regarding this theme - 'assessment process using the ICF-CY as reference framework', three main categories (Figure 2) were identified along professionals discourse: (1) the ICF-CY utility for special education assessment and eligibility purposes (112 from a total of 326 units of meaning about the theme); (2) the underlying procedures in the ICF-CY use - challenges managing the ICF-CY (120 units of meaning); and (3) the implied factors on the ICF-CY use

- changes or supportive mechanisms that would improve the ICF-CY use (94 units of meaning). 
ICF-CY utility for special education assessment and eligibility purposes

Positive and negative positions were identified in professionals discourse. The posi- tive discourse was more prevalent (88.4\% of the 112 units of meaning about the cat- egory), reporting that the ICF-CY use: allowed a better understanding of students' needs (62 units of meaning), a greater description of influent environmental factors (21 units of meaning) and has supported intervention planning (16 units of mean- ing). These assumptions highlighted that the ICF-CY use has supported a more spe- cific and detailed assessment, prompting better structured and organised assessment processes.

'We have much more information about students that we had previously' ; 'It helped us to think and to identify what students' are able to do and what is the severity of their difficulties'; 'makes us think about barriers and positive things that students have'; 'we can figure out much better what to do in the education plan' 
Table 2. Number, percentage and mean of spoken words and verbal interventions, and percentage of meaning units produced by each professional group in the six focus group topics.

\begin{tabular}{|c|c|c|c|c|c|c|c|}
\hline & \multicolumn{3}{|c|}{$\begin{array}{c}\text { Spoken words } \\
\text { Total no. }=260,832\end{array}$} & \multicolumn{3}{|c|}{$\begin{array}{l}\text { Verbal interventions } \\
\text { Total no. }=3545\end{array}$} & \multirow{2}{*}{$\begin{array}{c}\text { Meaning units total no. }=2589 \\
\text { Percentage }\end{array}$} \\
\hline & Number & Percentage & Average & Number & Percentage & Average & \\
\hline Special education teachers $(n=41)$ & 89,252 & 34.2 & 2176.9 & 1252 & 35.3 & 30.5 & 32.4 \\
\hline Elements from school board $(n=34)$ & 59,537 & 22.8 & 1751.1 & 788 & 22.2 & 23.2 & 25.3 \\
\hline Regular education teachers $(n=80)$ & 64,835 & 24.9 & 810.4 & 891 & 25.1 & 11.1 & 20.7 \\
\hline Psychologists $(n=27)$ & 40,315 & 15.5 & 1493.2 & 546 & 15.5 & 20.2 & 18.6 \\
\hline Professionals from $\operatorname{IRC}^{*}(n=10)$ & 6893 & 2.6 & 689.3 & 68 & 1.9 & 6.8 & 2.9 \\
\hline
\end{tabular}

"Professionals from IRC include mainly occupational therapists and speech therapists. 


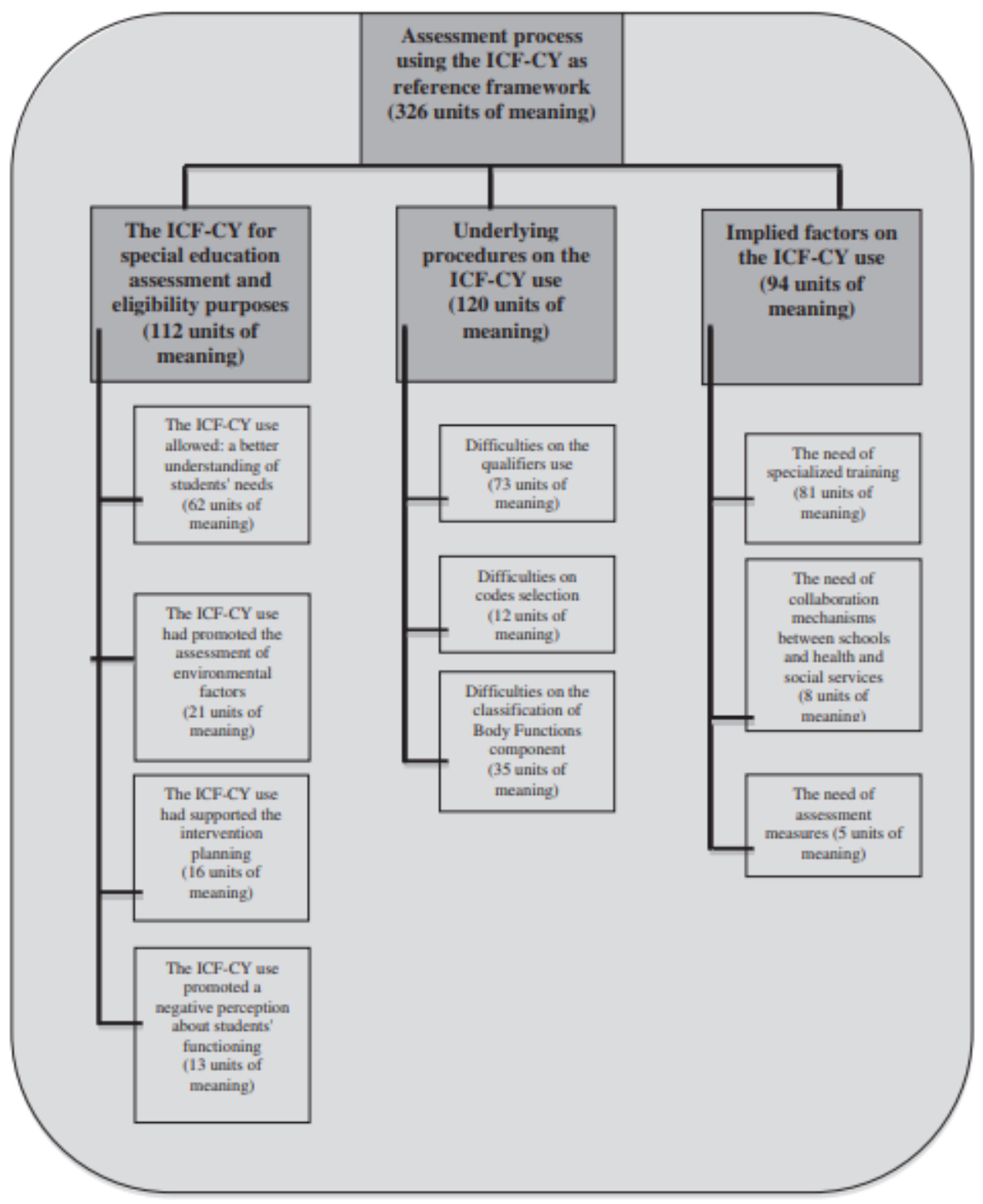

Figure 2. Categories and subcategories identified along the contents regarding the ICF-CY use on assessment process.

With a lower prevalence- 13 units of meaning (11.6\%) - an opposite view was also reported, pointing a negative impact of the ICF-CY use. Arguments considered that the ICF-CY use promoted a negative perception about students' functioning - focused on impairments and disabilities finding its contents excessively centred on medical issues and not applicable to educational contexts:

'it lthe checklist! only lists defects of students in physical, intellectual and emotional areas'; 'I can't see how ICF use can be adapted to educational context' 
Special education teacher and psychologists were the main professionals contrib- uting to both positive and negative positions about the ICF-CY utility - pertaining to those groups 55 of the 99 positive units of meaning and 10 of the 13 negative units of meaning (Table 3).

\section{Underlying procedures in the ICF-CY use}

Professionals referred difficulties regarding using the qualifiers and selecting the appropriate codes to describe students' functioning. Qualifiers use was the most mentioned challenge (73 of the 120 units of meaning about the category) - namely establishing criteria to decide which qualifiers should be chosen regarding the sever- ity/ magnitude of impairments or limitations/restrictions.

the boundary between severe (3) and complete (4) qualifiers is not clear and defined for us.

Not always we are sure if our decisions are wright or wrong

Related to the large spectrum of codes provided by the ICF-CY, the selection of codes that best describe students' functioning profile was perceived as a challenge by professionals (12 units of meaning).

I have the idea that the ICF is a 'world' of things and details. I'm always lost when I use it, I'm not able to identify what codes are more important and appropriate for stu- dents

Other mentioned difficulty - 35 units of meaning - was the classification of Body Functions component. The need of involving professionals that are experts on that component and the mentioned poor collaboration between health services and educational team seems to base the experienced challenges: 'Sometimes we need medical opinions and not always this professionals are available to help us'.

As observed in the previous category, the special education teacher and psychol- ogist were the main professionals reporting the underlying procedures on the ICF- CY use, pertaining to those groups 103 of the 120 units of meaning identified on this category (Table 3). 
Implied factors in the ICF-CY use

Along the discourse about needed supports or changes that would improve the ICF- CY use, three main factors were highlighted: (1) the need of specialised training (81 of 94 units of meaning about the theme); (2) greater collaboration mechanisms between schools and health and social services (8 units of meaning); and (3) the development of assessment measures (5 units of meaning).

(1) The expansion of the training programme prompted by the Education Ministry disseminated just after the decree-law promulgation - to all key professionals implied on the decree-law implementation, namely for school principals and health professionals, were highlighted as a support needed for a well-succeed change. The training on the ICF-CY use and on the decree- law implementation was pointed out as a key factor for prompting the adop- tion of common language and procedures. 
Table 3. Number (percentage) of units of meaning on the identified categories and subcategories, produced by each professional group.

\begin{tabular}{|c|c|c|c|c|c|c|}
\hline Categories & Subcategories & $\begin{array}{l}\text { Special } \\
\text { education } \\
\text { teachers } \\
(n=41)\end{array}$ & $\begin{array}{l}\text { Elements from } \\
\text { school board } \\
\quad(n=34)\end{array}$ & $\begin{array}{c}\text { Regular } \\
\text { education } \\
\text { teachers } \\
(n=80)\end{array}$ & $\begin{array}{l}\text { Psychologists } \\
\quad(n=27)\end{array}$ & $\begin{array}{l}\text { Professionals } \\
\text { from IRC } \\
(n=10)\end{array}$ \\
\hline \multirow{4}{*}{$\begin{array}{l}\text { The ICF-CY for special } \\
\text { education assessment and } \\
\text { eligibility purposes } \\
\text { (112 units of meaning) }\end{array}$} & $\begin{array}{l}\text { The ICF-CY use allowed: a better } \\
\text { understanding of students' needs } \\
\text { ( } 62 \text { units of meaning) }\end{array}$ & $17(27.4 \%)$ & $12(19.4 \%)$ & $15(24.2 \%)$ & $16(25.8 \%)$ & $2(3.2 \%)$ \\
\hline & $\begin{array}{l}\text { The ICF-CY use had promoted the } \\
\text { assessment of environmental factors } \\
\text { ( } 21 \text { units of meaning) }\end{array}$ & $8(38.1 \%)$ & $6(28.6 \%)$ & $3(14.3 \%)$ & $4(19.0 \%)$ & $0(0 \%)$ \\
\hline & $\begin{array}{l}\text { The ICF-CY use had supported the } \\
\text { intervention planning ( } 16 \text { units of meaning) }\end{array}$ & $7(43.8 \%)$ & $6(37.5 \%)$ & $0(0 \%)$ & $3(18.8 \%)$ & $0(0 \%)$ \\
\hline & $\begin{array}{l}\text { The ICF-CY use promoted a negative } \\
\text { perception about students' functioning } \\
\text { ( } 13 \text { units of meaning) }\end{array}$ & $7(53.8 \%)$ & $1(7.7 \%)$ & $1(7.7 \%)$ & $3(23.1 \%)$ & $1(7.7 \%)$ \\
\hline \multirow{3}{*}{$\begin{array}{l}\text { Underlying procedures on } \\
\text { the ICF-CY use ( } 120 \\
\text { units of meaning) }\end{array}$} & $\begin{array}{l}\text { Difficulties on the qualifiers use } \\
\text { ( } 73 \text { units of meaning) }\end{array}$ & $36(49.3 \%)$ & $3(4.1 \%)$ & $2(2.7 \%)$ & $26(35.6 \%)$ & $6(8.2 \%)$ \\
\hline & $\begin{array}{l}\text { Difficulties on codes selection } \\
\text { ( } 12 \text { units of meaning) }\end{array}$ & $6(50.0 \%)$ & $1(8.3 \%)$ & $1(8.3 \%)$ & $4(33.3 \%)$ & $0(0 \%)$ \\
\hline & $\begin{array}{l}\text { Difficulties on the classification of Body } \\
\text { Functions component ( } 35 \text { units of meaning) }\end{array}$ & $17(48.6 \%)$ & $2(5.7 \%)$ & $2(5.7 \%)$ & $14(40.0 \%)$ & $0(0 \%)$ \\
\hline \multirow{3}{*}{$\begin{array}{l}\text { Implied factors on the } \\
\text { ICF-CY use ( } 94 \text { units } \\
\text { of meaning) }\end{array}$} & $\begin{array}{l}\text { The need of specialized training ( } 81 \text { units } \\
\text { of meaning) }\end{array}$ & $33(40.7 \%)$ & $6(7.4 \%)$ & $11(13.6 \%)$ & $27(33.3 \%)$ & $4(4.9 \%)$ \\
\hline & $\begin{array}{l}\text { The need of collaboration mechanisms } \\
\text { between schools and health and social } \\
\text { services ( } 8 \text { units of meaning) }\end{array}$ & $2(25.0 \%)$ & $5(62.5 \%)$ & $0(0 \%)$ & $1(12.5 \%)$ & $0(0 \%)$ \\
\hline & $\begin{array}{l}\text { The need of assessment measures } \\
\text { ( } 5 \text { units of meaning) }\end{array}$ & $3(60.0 \%)$ & $0(0 \%)$ & $0(0 \%)$ & $2(40.0 \%)$ & $0(0 \%)$ \\
\hline
\end{tabular}

"Professionals from IRC include mainly occupational therapists and speech therapists. 
(2) It was also documented the need of a better linkage between Health and Education ministries in order to support the development of a common lan- guage between both systems: 'There were a lot of physicians refusing doing that !collaborate on assessment process!' . Efforts by professionals from exter- nal services describing assessment results with reference to the ICF language were reported as an emergent reality. Furthermore, the need of a greater con- nection between education and social services was documented in order to better prepare community responses to support post-school transitions.

(3) To reinforce the development of a common language and procedures under- lying the ICF-CY use, it was highlighted the need of being available a wider spectrum of assessment measures that can meet the ICF-CY taxonomy and the conceptual model. Development and availability of participation and environment-oriented measures were mentioned as being of priority need.

As Table 3 shows, similarly with previous categories, there was a greater involvement of special education teachers and psychologists discussing the implied factors on the ICFCY use, specifically highlighting the need of ICF-CY training and of assessment measures. The creation of effective communication systems and routines between school-based and external professionals was a need revealed with particular prominence by elements of school board.

\section{Discussion}

Through focus group interviews, in this study, we intended to analyse professionals' opinions about the ICF-CY use on assessment and eligibility procedures . Associated challenges and difficulties were examined, reflecting on the possible recommenda- tions to prompt a multidimensional approach on special educational assessment and intervention planning.

As mentioned before, the professionals' opinion about the contribution of the ICF-CY on the assessment process was one of the questions in focus. An important opinion of the professionals was that the development of assessment processes with reference to the ICFCY allowed a deeper understanding of the students and their needs. It was mentioned that the ICF-CY use would lead them to better emphasise what students do (i.e. students' Activities and Participation) rather than documenting only impairments or deficits. In a similar way, professionals assumed that the ICF-CY use prompted the inclusion of environmental factors as assessment targets - analysing how the environment can be a 
barrier or a facilitator for the student functioning.

The improved attention provided to environmental factors was a key reason argued by professionals to base the assumption that the ICF-CY use prompted a more rigorous and comprehensive approach to students' needs. The achieved envi- ronmental focus contributed also to the assumption that the resulting functioning profiles described through the ICF-CY framework - can better base the interven- tion planning, specifically the IEPs design.

This data - congruent with other studies' conclusions that emphasise the role of the ICF-CY in describing an holistic picture of students' functioning (e.g. De Polo et al. 2009; Tadema, Vlaskamp, and Ruijssenaars 2005) - seems, then, to suggest that the ICF-CY use embodies an important step towards a progressive distancing from onedimensional approaches, whose utility was restricted to eligibility purposes (not providing useful information for supports planning). As suggested in profes- sional discourse, there is an emerging continuity between assessment and interven- tion processes that seems to reinforce that the decision to base the eligibility process on functioning profiles - with reference to the ICF-CY framework - represents a more clear rupture with what Wang, Reynolds, and Walberg (1987) stated as the big- gest mistake of the educational system: the restrict utility of the assessment process to base eligibility decision-making, not informing the intervention planning.

Naturally along with this step ahead on inclusive practices emerged a new set of needs and unsatisfied demands. Difficulties and challenges were pointed out by pro- fessionals and were mainly related to these three features: (1) the need of assessment tools that can provide information about the environmental influences on students functioning; (2) the establishment of better collaboration mechanisms between school-based and external professionals; and (3) professionals' ICF-CY training.

It was reported that challenges experienced in qualifying the severity level of stu- dents' impairments and limitations/restrictions - through professionals' opinion - were related to the need of being available a wider spectrum of assessment tools. This study finding is coherent with the need - emphasised by other studies (e.g. Guscia et al. 2006 ; Whiteneck and Dijkers 2009) - of linking existing measurements to the ICF-CY codes and of building new assessment measures congruent with the ICF-CY framework. In fact, the dynamic proprieties of the ICF-CY need measures that provide information about the capacity and performance qualifiers with refer- ence to environment facilitators and barriers.

Another challenge pointed out was the establishment of better collaboration mechanisms between school-based and external professionals. In fact, as mentioned by the professionals, the holistic view of students' functioning prompted by ICF-CY use demands more efficient 
collaborative mechanisms between professionals and services - demanding more time for discussion between school-based professionals and efficient mechanisms of information sharing between professionals of external services. It was reported that organising to create appropriate conditions to have common moments for discussion between school-based professionals was a chal- lenge; nevertheless, the biggest difficulties were related to the collaboration between services. The mentioned difficulties in Body Functions classification are symptom- atic of the need of making stronger the connection between schools and health ser- vices.

Finally, regarding training demands, the need of amplifying the ICF-CY training to all persons that collaborate in special education assessment and intervention (including physicians, parents and other educational professionals) was emphasised as a key factor. In professionals' opinion, the creation of structured programmes of knowledge dissemination - large enough to cover all key elements - would support the change implementation on the assessment procedures. Also, the content coverage of the training programmes to different features and conceptual foundations of the Decree-Law No. 3/2008 would clarify the underlying reasons for the introduction of the ICF-CY as reference framework on special education field and prevent miscon-ceptions regarding the eligibility criteria.

Based on the larger number of meaning units identified in special education teachers and psychologists discourse, we may conclude that both are key elements professionals implied on the ICF-CY use in the assessment process. In addition, this study finding seems to suggest that the transferring of the responsibility for IEP coordination to regular education teachers is yet an emergent process.

The reported challenges seem to contribute to the fact that the first moment of change (i.e. first year) meant for most of the professionals involved only the applica- tion of a new language into the old and fragmented schemes of disability under- standing - mostly centred on students' body function impairments and activities limitations (Sanches-Ferreira, Simeonsson, et al. 2013). These data reinforce that the ICF-CY use per se does not mean the accomplishment of a multidimensional approach, but represents an evolutionary process that depends on multiple variables.

In Portugal, the ICF-CY use in education context meant a substantial input considering environmental influence on students' participation. An integrated and dynamic view of students' functioning - considering capacity and performance levels with reference to environmental factors - that can base the definition of inter- vention strategies is yet an unaccomplished stage that needs to be supported by developments in research, school organisation, professionals' beliefs and policy dimensions. 


\section{Conclusions}

From this data - collected from a national representative sample - we can conclude that professionals' opinion about the ICF-CY use is positive concerning the congru- ence of its conceptual framework and the needed inclusive approach; however, the optimisation of its use in the educational context depends on the development of key support conditions. Further steps in order to improve the ICF-CY use in Portuguese educational systems includes the development of: assessment tools able to cap- ture environmental influences on students' functioning; specialised training; and mechanisms for a more efficient collaboration between school-based and external professionals.

\section{References}

Altman, B. M. 2001. "Disability Definitions, Models, Classification Schemes, and Applica- tions." In Handbook of Disability Studies, edited by G. L. Albrecht, K. D. Seelman, and M. Bury, 97122. London: Sage.

Bardin, L. 1977. L'analyse de contenu [The Content Analysis]. Paris: Presses Universitaires de France.

Bijou, S. W., and D. Baer. 1978. Behavior Analysis of Child Development. Englewood Cliffs, NJ: Prentice-Hall .

Capucha, L., F. Pereira, A. Crespo, C. Correia, F. Cavaca, F. Croca, G. Breia, and M. Micaelo. 2008. Educar;iio especial - manual de apoio a pratica [Special Education - Manual to

Support the Practices]. Lisboa: Direc9ao-Geral de Inova9ao e de Desenvolvimento Curricular (DGIDC).

De Polo, G., M. Prada!, S. Bortolot, M. Buffoni, and A. Martinuzzi . 2009 . "Children with Disability at School: The Application of ICF-CY in the Veneto Region." Disability \& Rehabilitation 31 (sl): S67-S73. doi:10.3109/09638280903317880 .

Decreto-Lei No. 3/2008 (Decree-Law No. 3/2008). 2008. Ministerio da Educar;iio . Diario da Republica [Ministry of Education. Republic Diary]. Serie No.4-7 de Janeiro [January]: 154164.

Ebersold, S., and P. Evans. 2008. "A Supply-side Approach for a Resource-based Classifica- tion System." In Disability Classification in Education: Issues and Perspectives, edited by L. Florian and M. J. McLaughlin, 31-46. Thousand Oaks, CA: Corwin Press.

European Agency for Special Needs and Inclusive Education. 2009 . Identification of Special Educational Needs - Portugal. Accessed February 3. http://www.european-agency.org / country-information/portugal/national-oveIView /identification-of-special-educational-needs 
European Agency for Special Needs and Inclusive Education. 2011. Participation in Inclu- sive Education - A Framework for Developing Indicators. Denmark: European Agency for Special Needs and Inclusive Education.

Florian, L., J. Hollenweger, R. Simeonsson, K. Wedell, S. Riddell, L. Terzi, and A. Holland. 2006. "Cross-cultural Perspectives on the Classification of Children with Disabilities." The Journal of Special Education 40 (1): 36-45.

Fusaro, G., M. Maspoli, and G. Vellar. 2009. "TheCF-based Functioning Profiles of School Children in Care with the Neuropsychiatric Community SeIVices in the Piedmont Region: Evidences for Better Caring and Programming." Disability \& Rehabilitation 31 (s1): S61-S66.

Guscia, R., S. Ekberg, J. Harries, and N. Kirby. 2006. "Measurement of Environmental Constructs in Disability Assessment Instruments." Journal of Policy and Practice in Intellectual Disabilities 3 (3): 173-180.

Hollenweger, J. 2008. "Cross-national Comparisons of Special Education Classification Systems." In Disability Classification in Education: Issues and Perspectives, edited by

L. Florian and M. McLaughlin, 11-27. Thousand Oaks, CA: Corwin Press.

Hollenweger, J. 2011. "Development of anCF-based Eligibility Procedure for Education in Switzerland." BMC Public Health 11 (S7): 1-8.

Norwich, B. 2008. "Perspectives and Purposes of Disability Classification Systems: Implica- tions for Teachers and Curriculum." In Disability Classification in Education : Issues and Perspectives, edited by L. Florian and M. McLaughlin, 131-149. Thousand Oaks, CA: Corwin Press.

Sanches-Ferreira, M., P. Lopes-dos-Santos, S. Alves, M. Santos, and M. Silveira-Maia. 2013. "How Individualised are the Individualised Education Programmes (IEPs): An Analysis of the Contents and Quality of the IEPs Goals." European Journal of Special Needs Edu-cation 28 (4): 507-520.

Sanches-Ferreira, M., R. Simeonsson, M. Silveira-Maia, S. Alves, A. Tavares, and S. Pinhe- iro. 2010. Projecto da Avaliar;iio Externa da Implementar;iio do Decreto-Lei n. ${ }^{\circ}$ 32008: Relat6rio Final [External Evaluation Project of Decree-Law No. 3/2008 Implementation]. Lisboa: Direc9aoGeral de Inova9ao e de Desenvolvimento Curricular [Lisbon: Director- ate-General for Innovation and Curriculum Development]. Accessed February 3. http :// www.dgidc.min-edu .pt/educacaoespecial/dat a/ensinoespecial/estudo_simeonsson.pdf

Sanches-Ferreira, M., R. Sirneonsson, M. Silveira-Maia, S. Alves, A. Tavares, and S. Pinheiro . 2013. "Portugal's Special Education Law: Implementing the International Classification of Functioning, Disability and Health in Policy and Practice ." Disability \& Rehabilitation 35 (9-10): 868-873.

Shonkoff, J. P. 2000. "Science, Policy, and Practice: Three Cultures in Search of a Shared Mission." Child Development 71 (1): 181-187.

Silveira-Maia, M., P. Lopes-dos-Santos, M. Sanches-Ferreira, A. Tavares, S. Alves, and S. Pinheiro . 2012. The Use of the International Classification of Functioning, Disability and Health (ICF) Framework on Educational Planning: Promoting an Environmental Approach . International Journal for Cross-Disciplinary Subjects in Education 2 (2): 970-977. 
Simeonsson, R. J. 2006. "Defining and Classifying Disability in Children." In Disability in America : A New Look, edited by M. J. Field, A. M. Jette, and L. Martin, 66-87. Washington, DC: National Academies Press.

Simeonsson, R. J., N. E. Simeonsson, and J. Hollenweger. 2008. "International Classification of Functioning, Disability and Health for Children and Youth: A Common Language for Special Education." In Disability Classification in Education: Issues and Perspectives, edited by L. Florian and M. McLaughlin, 207-217. Thousand Oaks, CA: Corwin Press.

Tadema, A. C., C. Vlaskamp, and W. Ruijssenaars . 2005. "The Development of a Checklist of Child Characteristics for Assessment Purposes." European Journal of Special Needs Education 20 (4): 403-417.

Tokunaga, A. 2008. "The Attempt of the Practical Application of International Classification of Functioning, Disability, and Health (ICF) as a Tool for Collaboration among Various Professionals: A Perspective on its Applicability to 'Individualized Educational Support Plan'." NISE Bulletin 9: 1-26.

UNESCO . 1994. The Salamanca Statement and Framework for Action on Special Needs Education. World Conference on Special Needs Education: Access and Quality, Salamanca, Spain.

United Nations. 2006. Convention on the Rights of Persons with Disabilities and Optional Protocol. New York: United Nations.

Wang, M. C., M. C. Reynolds, and H. J. Walberg. 1987. Handbook of Special Education : Research and Practice. 1 vols. Oxford: Pergamon.

Whiteneck, G., and M. Dijkers. 2009. 'Difficult to Measure Constructs: Conceptual and Methodological Issues Concerning Participation and Environmental Factors." Archives of Physical Medicine and Rehabilitation 90 (11): S22-S35.

WHO (World Health Organization). 2001. International Classification of Functioning, Disability and Health. Geneva: World Health Organization.

WHO (World Health Organization). 2007. International Classification of Functioning, Disabil- ity and Health - Versionfor Children and Youth. Geneva: World Health Organization . 